\title{
aIIRC
}

\section{A IMPLEMENTAÇÃO DA TRANSFERÊNCIA DO DIREITO DE CONSTRUIR NA REGULARIZAÇÃO DE PARAISÓPOLIS (SP)}

The Implementation Of The Transfer Of The Right To Build In The Regularization Of Paraisópolis (Sp)

\section{Thiago Marrara}

Universidade de São Paulo - USO, São Paulo, SP, Brasil

Lattes: http://lattes.cnpq.br/5001783167154079. Orcid: https://orcid.org/0000-0002-1524-568X

E-mail: marrara@usp.br

\section{Pedro Rodrigo Campelo Lima}

Universidade de São Paulo - USO, São Paulo, SP, Brasil

Lattes: http://lattes.cnpq.br/8921948076714110. Orcid: https://orcid.org/0000-0002-1524-568X

E-mail: pedro.lima_ap@hotmail.com

Trabalho enviado em 02 de julho de 2021 e aceito em 01 de setembro de 2021

\section{(c) (i)}

This work is licensed under a Creative Commons Attribution 4.0 International License. 


\section{RESUMO}

O presente trabalho busca analisar a implementação da transferência do direito de construir no processo de regularização do Complexo de Paraisópolis, na cidade de São Paulo (SP). Para tanto, foram realizadas pesquisas bibliográfica e documental entre outubro de 2020 e março de 2021. Inicialmente, contextualiza-se a evolução da urbanização de favelas no Brasil. Analisa-se também a evolução legislativa da transferência do direito de construir na política urbana brasileira e no município de São Paulo. Em seguida, apresenta-se o estudo de caso, relacionando a experiência de regularização de Paraisópolis com a utilização da transferência do direito de construir. Conclui-se que o projeto gerou resultados importantes, mas não solucionou o déficit habitacional existente na comunidade.

Palavras-chave: transferência do direito de construir; Paraisópolis; regularização; urbanização; estudo de caso

\section{ABSTRACT}

This paper aims to analyze the implementation of the transfer of the right to build in the regularization process of the Complex of Paraisópolis, in the city of São Paulo (SP). To this goal, bibliographical and documentary research was carried out during October 2020 and March 2021. Initially, the evolution of slum urbanization in Brazil is contextualized. It also analyzes the legislative evolution of the transfer of the right to build in Brazilian urban policy and in the municipality of São Paulo. Afterwards, the case study is presented, relating the experience of regularization of Paraisópolis with the use of the transfer of the right to build. It is concluded the project generated important results, but did not solve the housing deficit in the community.

Keywords: transfer of the right to build; Paraisópolis; regularization; urbanization; case study 


\section{INTRODUÇÃO}

O propósito deste artigo é apresentar a pesquisa sobre a regularização urbanística do Complexo de Paraisópolis, na cidade de São Paulo, a partir da implementação da transferência do direito de construir (TDC).

O tema é relevante porque, em diversas cidades brasileiras, parcela significativa da população vive em aglomerados subnormais, assim compreendidos os cortiços, as favelas, invasões, grotas, baixadas e os mocambos. Um dos principais desafios para a regularização fundiária desses locais é o custo elevado dos processos de desapropriação, que geralmente são necessários para a execução das obras. Diante disso, o município de São Paulo utilizou a TDC como uma alternativa às desapropriações em Paraisópolis, incentivando a doação de imóveis na comunidade. Trata-se de uma inciativa que merece ser estudada com atenção, pois pode servir de paradigma para outras experiências de regularização no país.

As técnicas de pesquisa utilizadas foram o levantamento bibliográfico e a análise de relatórios públicos e documentos informacionais da Prefeitura de São Paulo. A pesquisa bibliográfica ocorreu no Portal de Teses e Dissertações da CAPES e nas bases de dados dos periódicos Cadernos Metrópole, Revista de Direito da Cidade, Revista Brasileira de Direito Urbanístico e Revista Brasileira de Estudos Regionais e Urbanos, entre outubro de 2020 e março de 2021. Os raciocínios desenvolvidos nesta investigação foram do tipo dedutivo, para a análise das normas de direito urbanístico, e indutivo, partindo-se do estudo de caso de Paraisópolis.

O trabalho encontra-se subdividido em quatro seções com o objetivo de apresentar um panorama amplo acerca do tema em estudo. Na primeira, apresenta-se um histórico sucinto do processo de urbanização de favelas no Brasil, destacando a evolução das primeiras políticas, que se pautavam na remoção, até as mais recentes, que buscam a regularização dessas áreas através dos instrumentos urbanísticos. Na segunda, faz-se um breve histórico da transferência do direito de construir no ordenamento brasileiro e na legislação do município de São Paulo. Na terceira, analisa-se o processo de regularização urbanística do Complexo de Paraisópolis e se discute a contribuição da TDC para a consecução dos objetivos traçados. Na quarta seção, são apresentadas as conclusões da pesquisa. 
Sem a pretensão de exaurir o debate a respeito do tema, esta pesquisa busca contribuir para as discussões acerca da regularização de favelas no país a partir do uso de instrumentos da política urbana. Acredita-se que as conclusões apresentadas apontarão para novas reflexões sobre o tema, permitindo o aperfeiçoamento dos institutos pesquisados.

\section{BREVE HISTÓRICO DA URBANIZAÇÃO DE FAVELAS NO BRASIL}

A ocupação irregular do solo urbano pela população pobre, com a consequente formação de favelas em várias cidades brasileiras, é um fato que decorre do processo de urbanização excludente implementado no país principalmente a partir do século XX. Denaldi et al. (2016, p. 102) asseveram que a favela surgiu como uma alternativa de habitação para as pessoas que não conseguiam o acesso à moradia por meio do Estado ou do mercado imobiliário formal, sobretudo porque no Brasil os gastos com a moradia nunca foram incorporados aos salários pagos aos trabalhadores.

Um exemplo de como esse processo de formação de assentamentos precários se deu nas principais cidades do país é apresentado por Lilia Schwarcz e Heloisa Starling, ao analisarem a constituição da primeira favela do Rio de Janeiro, localizada no morro da Providência, no início do século XX. De acordo com as autoras, o local começou a ser ocupado por ex-combatentes da guerra de Canudos, que acampavam nos arredores do então Ministério da Guerra para reivindicar moradias do Poder Público. Contudo, como as políticas de habitação da época eram ineficazes, a ocupação se tornou definitiva e, aos soldados, juntaram-se os negros libertos da escravização e as pessoas advindas da região Nordeste do país que se mudavam para a então capital federal (SCHWARCZ; STARLING, 2015, p. 337)

Durante grande parte do século XX, as políticas urbanas voltadas às favelas buscavam a sua erradicação, seja por considerá-las focos de contaminação e propagação de doenças, seja por associálas à criminalidade urbana, segundo Cardoso (2007, p. 220). Somente a partir da década de 1970 se observa uma mudança de orientação quanto às ações estatais direcionadas às favelas, dentre as quais se pode destacar a criação do programa PROMORAR, do Banco Nacional da Habitação (BNH), que disponibilizava empréstimos, repasses e financiamentos para a regularização fundiária e a urbanização dessas áreas (SANTOS, 2017, p. 63). Embora o objetivo do programa fosse a legalização dos lotes, com a consequente incorporação da população pobre ao mercado imobiliário formal, sua operacionalização demandou, em alguns casos, remoções e reassentamentos de moradores para a 
consecução de obras públicas, como prolongamento de vias e construção de moradias populares, conforme Flavia Brasil (2003, p. 52).

O PROMORAR não apresentou resultados significativos ao longo de sua vigência e as favelas somente voltaram a ser objeto de uma nova política pública federal com a criação do programa Habitar Brasil (PHB) no ano de 1993. O programa tinha como público-alvo as famílias com renda de até três salários mínimos que moravam em áreas sem condições de habitabilidade e que ainda não haviam sido atendidas por outro programa habitacional. Por meio do PHB, Estados e Municípios recebiam verbas para o financiamento de projetos de asfaltamento, instalação de energia elétrica, saneamento e construção de moradias populares em áreas de favela, sendo esses recursos repassados pelo então Ministério do Bem-Estar Social através da Caixa Econômica Federal. Apesar de relevante, o programa também não gerou os resultados esperados. Souza (2008, p. 72-74) atribui esse insucesso à falta de orçamento para o financiamento dos projetos no contexto de austeridade fiscal da época.

É importante pontuar que, embora distintas, a regularização fundiária e a urbanização de assentamentos precários são medidas interligadas que buscam concretizar direitos sociais da população de baixa renda. A regularização fundiária garante a titulação da posse aos moradores da área, enquanto a urbanização assegura o acesso a equipamentos comunitários e serviços públicos. Por isso, Carvalho Filho $(2013,71-72)$ afirma que a consequência natural da regularização de um assentamento precário é a sua urbanização, pois os moradores têm a pretensão de ver a área dotada de infraestrutura urbana, como saneamento básico, energia elétrica e pavimentação. Logo, a regularização urbanística é um processo que depende tanto de medidas jurídicas quanto sociais e ambientais para se realizar.

Durante a década de 1980, ou seja, antes da criação do PHB, algumas iniciativas municipais de regularização foram executadas com o propósito de urbanizar assentamentos precários. Dignos de nota, nesse sentido, são o Projeto Rio e o programa Cada família Um Lote (CFUL), ambos implementados no Rio de Janeiro, e o Programa Municipal de Regularização de Favelas (PROFAVELA), implementado em Belo Horizonte, em 1983. Rubio (2017, p. 123) assinala que, no mesmo período, ações semelhantes foram executadas em São Paulo e Diadema com resultados pontuais.

Outras experiências federais relacionadas à regularização de favelas foram levadas a efeito ao longo da década de 1990 e nos primeiros anos da década de 2000, como o Programa de Ação Social e Saneamento (PASS), Pró-Moradia e Habitar Brasil/BID, todas sem resultados muito relevantes em razão da escassez dos recursos alocados (CARDOSO; ARAGÃO; JAENISCH, 2017, p. 19-21). Porém, com a criação do Programa de Aceleração do Crescimento - Urbanização de Assentamentos Precários (PAC- 
UAP), em 2007, e do Programa Minha Casa Minha Vida (PMCMV), em 2009, grandes aportes financeiros voltaram a ser investidos pelo Governo Federal na urbanização de assentamentos precários no país, gerando importantes repercussões nas cidades, segundo Antonucci e Samora (2016, p. 13).

Como exemplo da implementação do PAC-UAP, Fabiana Izaga e Margareth da Silva Pereira apresentam o caso da cidade do Rio de Janeiro, onde algumas comunidades foram selecionadas pelo programa. Segundo as autoras:

Entre outras ações, o PAC selecionou vários assentamentos "subnormais" a serem contemplados, entre os quais as três favelas: PavãoPavãozinho/Cantagalo, Complexo do Alemão e Favela da Rocinha. Estas favelas receberam verbas do setor de infraestrutura social e urbana do PAC-RJ, no valor de aproximadamente $\mathrm{R} \$ 1,2$ bilhões (US\$ 525 milhões), do total de $\mathrm{R} \$ 125,7$ bilhões (US\$ 55 bilhões) dos investimentos do programa para o estado até 2010. [...] Nas três comunidades citadas foram realizadas obras nas redes de abastecimento de água, esgotamento sanitário, drenagem, iluminação pública, além de alargamento e pavimentação de ruas, construção de novas unidades habitacionais e melhorias nas existentes e construção de equipamentos públicos. No que se refere à mobilidade, o diferencial do PAC consiste na elaboração de intervenções que buscam estabelecer conexões com a rede de transporte urbano existente, além de atuar na escala local através da estratégia anteriormente estabelecida de alargamento e conectividade de cada área ao sistema viário (IZAGA; PEREIRA, 2014, p. 96-97).

De acordo com os dados do Governo Federal, foram previstos investimentos de 20,4 bilhões de reais para a regularização de mais de três mil assentamentos precários no país por meio do PACUAP e PMCMV (BRASIL, 2014, p. 192). Contudo, segundo dados oficiais, até o ano de 2018, apenas $27 \%$ (vinte e sete por cento) dessas obras haviam sido concluídas, perfazendo um total de 6,4 bilhões de reais em recursos. A maioria das obras foi finalizada entre os anos de 2015 e 2018 (quatrocentas e sessenta e nove), correspondendo a 3,5 bilhões de reais investidos em 1.820 municípios, o que não deixa de ser relevante frente ao baixo orçamento dos programas anteriores (BRASIL, 2018, p. 44).

Dentre as críticas formuladas ao PAC-UAP e ao PMCMV, pode-se citar a baixa aderência espacial entre o déficit e a produção de habitação de interesse social (HIS), bem como a demora na conclusão das obras, pois muitas sofreram paralisações ao longo de sua execução, conforme dados do próprio Governo Federal. Além disso, Balbim e Krause (2014, p. 199-200) criticam a falta de integração entre os dois programas e as demais políticas sociais, como as de geração de emprego e renda, que deveriam ser implementadas de maneira conjunta para o enfrentamento dos problemas estruturais nas comunidades beneficiadas. 
O processo de urbanização das comunidades do Cantagalo e do Pavão-Pavãozinho ilustra bem alguns desses problemas, conforme aponta Andreia Nogueira dos Santos. De acordo com o estudo desenvolvido pela autora, "as obras do PAC, tanto no Cantagalo, quanto no Pavão-Pavãozinho se encontram inacabadas e certas áreas das favelas apresentam aspecto de destruição e abandono, visto que muitas casas foram destruídas, e outras descaracterizadas, para a abertura de vias que não foram concluídas" (SANTOS, 2017, p. 89). A autora afirma também que, embora algumas obras do PAC-UAP tenham sido concluídas, como a instalação de um grande reservatório de água e a construção de prédios residenciais, a impressão dos moradores é de que o programa, assim como outros que o precederam, não gerou os resultados esperados pelas comunidades (SANTOS, 2017, p. 101).

Raquel Rolnik et al (2015, p. 131), ao analisarem programas como PMCMV e PAC-UAP, criticam o protagonismo das construtoras na proposição de projetos e na seleção de terrenos para HIS, principalmente porque tal protagonismo resulta em uma reprodução do padrão periférico de moradia longe dos centros das cidades. Os autores afirmam que essas obras podem até criar subcentralidades importantes nas periferias das cidades, com a oferta de comércio e serviços, mas que, em razão do seu padrão urbanístico precário, essas áreas acabam tendo um desenvolvimento desigual em relação aos espaços centrais e privilegiados das cidades (ROLNIK et al, 2015, p. 146).

Portanto, infere-se que ainda existem muitas questões que precisam ser enfrentadas para que a regularização de aglomerados subnormais no país responda de maneira satisfatória às necessidades sociais da população. Ainda que o PAC-UAP e o PMCMV tenham recebido muitos recursos para a urbanização dessas áreas, a baixa produção de HIS, o atraso na execução das obras e a falta de articulação com outros programas sociais são alguns dos problemas que precisam ser resolvidos para que esses projetos resultem em efetiva melhoria da qualidade de vida dos moradores.

\section{A TDC NA REGULAÇÃO URBANÍSTICA BRASILEIRA E DO MUNICÍPIO DE SÃO PAULO}

Inicialmente, deve-se pontuar que diferentes instrumentos urbanísticos podem ser mobilizados para a execução de projetos de regularização urbanística, e essa articulação é importante, pois são múltiplos os problemas que precisam ser enfrentados nas comunidades.

Para o estudo de caso desta pesquisa, um desses instrumentos merece atenção, pois foi por meio dele que algumas ações do plano de regularização de Paraisópolis foram viabilizadas, como a construção de HIS. Trata-se da TDC, que é um instrumento de ordenação territorial previsto no Estatuto da Cidade (Lei n. 10.257/2001) e que vem sendo utilizado por alguns municípios brasileiros 
desde a década de 1970. Nesta seção, apresenta-se o histórico do instrumento e discute-se como ele pode ser uma alternativa às desapropriações.

Utilizando-se a TDC, é possível que o proprietário transfira o seu direito de construir para outro local ou aliene esse direito a terceiros. Contudo, para que essa transferência ocorra, o artigo 35, do Estatuto da Cidade, estabelece duas condições: (I) a previsão da TDC no plano diretor e (II) a existência de lei municipal que discipline o uso da TDC. Se um desses requisitos não for cumprido, o Poder Público não poderá autorizar administrativamente a transferência.

De acordo com o artigo 35, do Estatuto da Cidade, a TDC pode ser utilizada para os seguintes fins: (I) a implantação de equipamentos urbanos e comunitário, (II) a preservação de imóvel de relevância histórica, ambiental, paisagística, social ou cultural e (III) a execução de projetos de regularização em áreas com população de baixa renda e a construção de HIS. Como exemplo dessa última hipótese, Barcellar, Furtado e Newlands (2017, p. 4) citam a ocupação de terreno particular por pessoas hipossuficientes sem moradia. Por meio da TDC, é possível que o Poder Público municipal receba o imóvel em disputa como doação, autorizando o proprietário a construir em outra área do município, e, assim, permita que os ocupantes continuem a residir no local, mas agora de forma regular.

Luiz Alochio (2008, p. 138) afirma que o Poder Público sempre tem a prerrogativa de desapropriação dos imóveis nas hipóteses previstas em lei (como nos casos de regularização fundiária); porém, as limitações orçamentárias geralmente impedem o pagamento indenizações justas às pessoas desapropriadas, limitando a implementação do instituto. Dessa forma, a TDC pode ser uma alternativa e um incentivo aos particulares, pois permite tanto a venda de potenciais construtivos não utilizados quanto a doação de imóveis ao Poder Público em troca da possibilidade de se construir em outras áreas da cidade.

Segundo Bitencourt (2005, p. 18), as primeiras experiências brasileiras com o uso da TDC ocorreram na década de 1970, em um contexto de discussões sobre o solo criado e a necessidade de se garantir um equilíbrio entre as áreas edificadas e livres das cidades. Alguns municípios passaram a permitir que os proprietários doassem seus terrenos ao Poder Público para que, em contrapartida, pudessem exercer o seu direito de construir em outros locais da cidade, originando a TDC.

Nogueira (2019, p. 43) observa que o município de Porto Alegre foi um dos primeiros do país a possibilitar a alienação de potenciais construtivos não utilizados por meio da "reserva de índice construtivo", cujos recursos eram utilizados para custear obras públicas de melhoramento urbano na 
capital gaúcha. Experiências semelhantes foram implementadas em outras cidades do país, como Curitiba e São Paulo, ao longo da segunda metade do século XX.

Na cidade de São Paulo, a primeira legislação a dispor sobre a TDC foi a Lei Municipal $n$. 9.725/1984, que previa a sua utilização exclusivamente para imóveis de relevância histórica ou de excepcional valor artístico, cultural ou paisagístico, conforme Souza, Peretto e Seo $(2019$, p. 3). o objetivo da normativa era incentivar a conservação desses bens por meio da autorização de alienação do direito de construir para zonas contíguas mais permissivas, onde poderiam ser construídos novos empreendimentos. Segundo Louro e Silva e Campos (2016, p. 76), esse caráter preservacionista da TDC foi reforçado pela Lei Municipal n. 12.349/1997, que previa a sua utilização na Operação Urbana Centro.

As Operações Urbanas na cidade de São Paulo são intervenções realizadas em áreas delimitadas pelo Plano Diretor Estratégico (PDE) com o objetivo de qualificá-las estruturalmente, seja com a instalação de equipamentos públicos de uso comum, seja com atração de investimentos imobiliários, turísticos e culturais, por exemplo. Fontes $(2011$, p. 84) afirma que as Operações Urbanas são um redesenho do tecido urbano, econômico e social de certas áreas da cidade que devem ser disciplinadas tanto pelo PDE quanto por lei municipal específica. Como exemplos de intervenções dessa natureza já realizadas, tem-se a Operação Urbana Centro e a Operação Urbana Águas Espraiadas.

As hipóteses de utilização da TDC foram ampliadas com a edição do PDE de São Paulo de 2002 (Lei Municipal n. 13.430/2002) e, posteriormente, com a aprovação da Lei Municipal n. 13.885/2004, que disciplinava o parcelamento, uso e ocupação do solo urbano no município. O PDE de 2002 reproduzia em seu artigo 217 as mesmas possibilidades de utilização da TDC previstas no Estatuto da Cidade, evidenciando a influência que a lei federal exerceu sobre as leis municipais editadas após sua vigência. Por sua vez, a Lei Municipal n. 13.885/2004, que foi revogada em 2016 pela Lei Municipal n. 16.402/2016, dispunha sobre a TDC em seu artigo 24, fazendo remissões às disposições do PDE de 2002.

Com a edição do PDE de São Paulo de 2014 (Lei Municipal n. 16.050/2014), a TDC ganhou nova disciplina jurídica, desta feita com a previsão de seis hipóteses autorizativas de seu uso pelo artigo 123, a saber: (I) a preservação de bem de interesse histórico, paisagístico, ambiental, social ou cultural, (II) a execução de melhoramentos viários para a implantação de corredores de ônibus, (III) a implantação de parques planejados situados na Macrozona de Estruturação e Qualificação Urbana, (IV) a preservação de áreas de propriedade particular, de interesse ambiental, localizadas em ZEPAM, situadas na Macrozona de Estruturação e Qualificação Urbana, que atendam os parâmetros 
estabelecidos na LPUOS, (V) a execução de programas de regularização fundiária e urbanização de áreas ocupadas por população de baixa renda e (VI) a execução de programas de provisão de HIS.

Atualmente, a TDC pode ser operacionalizada de duas formas no município de São Paulo, ora por meio da doação do imóvel ao Poder Público, ora pela alienação do potencial construtivo não utilizado pelo imóvel cedente. Os casos em que não há a doação são os que envolvem imóveis tombados e de interesse ambiental, ou seja, são aqueles previstos nos incisos I e IV do artigo 123, do PDE. Nas demais hipóteses, segundo o artigo 126, do PDE, há a possibilidade de doação do imóvel e, dentre elas, está a regularização fundiária e urbanização de áreas habitadas por população de baixa renda. Essas possibilidades de doação foram primeiramente regulamentadas pelo Decreto Municipal n. 57.535/2016, mas hoje o são pelo Decreto Municipal n. 58.289/2018.

Flavia Peretto (2020, p. 104) afirma que o procedimento administrativo da TDC na cidade de São Paulo envolve a emissão de dois documentos pela Secretaria Municipal de Desenvolvimento Urbano (SMDU): a Declaração de Potencial Construtivo Passível de Transferência e a Certidão de Transferência de Potencial Construtivo. No primeiro documento consta a quantidade de metros quadrados que o imóvel pode transferir, enquanto no segundo consta o ato da transferência de potencial construtivo de um imóvel para o outro. Ainda de acordo com a autora, a apresentação da certidão é obrigatória para a requisição do alvará do imóvel receptor, pois será por meio dela que se atestará a transação do potencial construtivo e, assim, se isentará o proprietário do pagamento da outorga onerosa.

Uma última consideração em relação à TDC no município de São Paulo diz respeito à sua diferenciação da Transferência de Potencial Construtivo (TPC), que é um instrumento com características semelhantes à TDC, mas que com ela não se confunde. A TPC encontra-se disciplinada pela Lei Municipal n. 12.349/1997 e somente pode ser utilizada na área da Operação Urbana Centro. Logo, sua aplicabilidade é mais restrita que a da TDC. Embora os dois instrumentos coexistam na regulação urbanística de São Paulo, há críticas em relação à necessidade de se atualizar a disciplina da TPC, de modo a adequá-la às diretrizes do Estatuto da Cidade.

Nesse sentido, Paula Santoro, Flavia Peretto e Silvio Oksman afirmam:

A Transferência de Potencial Construtivo, como utilizada hoje na Operação Urbana Centro, difere da TDC, pois ela permite ao proprietário do imóvel tombado transferir até a metragem máxima estabelecida pelo coeficiente de aproveitamento da zona em que está inserido. Aí reside uma das críticas mais recorrentes ao instrumento: permite que o proprietário venha transferir o que não é dele, pois os direitos de construir acima do coeficiente de aproveitamento básico são públicos. O próprio Plano Diretor define que "o potencial construtivo 
adicional é bem jurídico dominical de titularidade da Prefeitura, com funções urbanísticas e socioambientais" (art. 116) (SANTORO; PERETTO, OKSMAN, 2018).

Enquanto a TDC permite que o proprietário transfira somente o correspondente ao seu direito básico de construir, observado o coeficiente de aproveitamento básico do terreno, a TPC autoriza a alienação do coeficiente de aproveitamento máximo do imóvel, o que a torna muito mais vantajosa para o proprietário. Diante disso, concorda-se com a necessidade de revisões na TPC, pois, ao permitir a alienação de direitos de construir que não pertencem ao proprietário, senão à coletividade, o instrumento coloca recursos públicos nas mãos de particulares, o que destoa de todas as diretrizes da política urbana.

Portanto, embora tenha um breve histórico na legislação urbanística federal, a TDC é um instrumento de grande importância que já vem sendo utilizado por certos municípios desde a segunda metade do século XX. Dentre os seus objetivos, estão a busca pelo equilíbrio da densidade das cidades e a gestão social da valorização da terra urbana. Além disso, a TDC pode ser utilizada para a regularização fundiária de áreas habitadas pela população pobre, evidenciando o cunho social do instrumento.

\section{O PROCESSO DE REGULARIZAÇÃO URBANÍSTICA DO COMPLEXO DE PARAISÓPOLIS}

O complexo de Paraisópolis está localizado na zona sul da cidade de São Paulo, na região da subprefeitura do Campo Limpo, distrito de Vila Andrade, próximo ao Morumbi. É formado pelas comunidades de Paraisópolis, Porto Seguro e Jardim Colombo. O complexo é considerado a segunda maior favela de São Paulo em população, com 42 mil habitantes, segundo Pizarro (2014, p. 106).

Paraisópolis é subdividida em cinco regiões, quais sejam: Centro, Antonico, Brejo, Grotão e Grotinho, sendo o Centro a parte mais antiga da comunidade e a que se localiza em sua área mais elevada. O Antonico e o Brejo são áreas cortadas por córregos que, em razão da falta de saneamento básico, historicamente alagam em períodos de maior pluviosidade. O Grotão e o Grotinho são consideradas as áreas de maior vulnerabilidade socioambiental da comunidade, pois abrigam uma população com renda muito baixa e que vive próximo a encostas sujeitas a deslizamentos, conforme Rezende (2019, p. 125-128).

Figura 1 - Divisão de Paraisópolis por regiões 


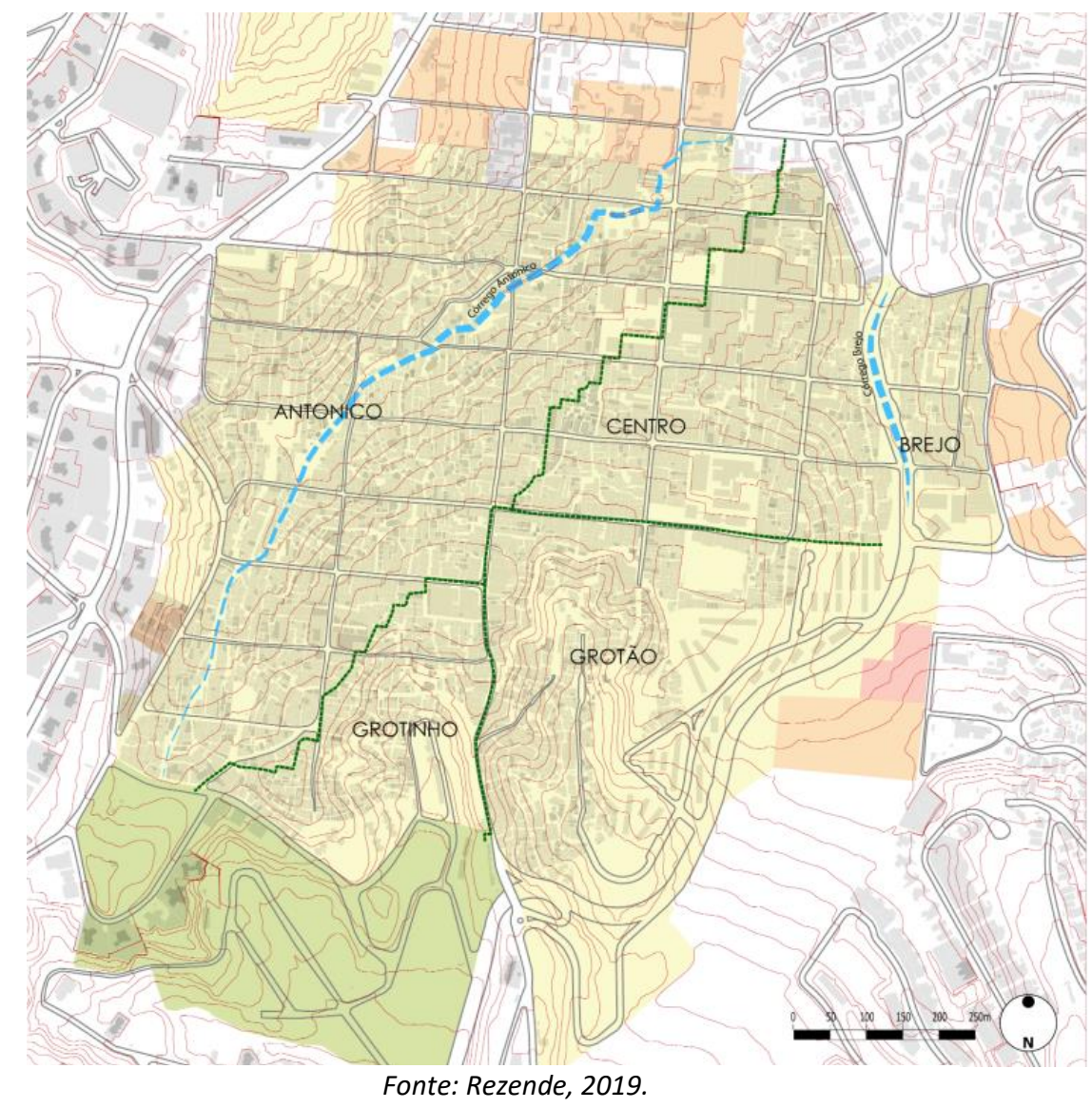

A formação de Paraisópolis remonta ao início do século XX, quando a antiga fazenda do Morumbi, que pertencia à família Dedenrichesen, foi loteada em aproximadamente 2.200 chácaras para ser vendida. Parte dessas terras, porém, foi ocupada de forma ilegal por grileiros que pretendiam lucrar com a especulação imobiliária na região. Segundo Alessi $(2009$, p. 56), a ocupação irregular se intensificou a partir da década de 1960 com a expansão do mercado imobiliário e o aumento de fluxos migratórios em direção à zona sul de São Paulo, que à época oferecia muitas oportunidades de emprego na construção civil.

Paraisópolis foi reconhecida como assentamento pela Prefeitura de São Paulo no ano de 1968 por meio da lei de zoneamento geral do município. No ano de 1978, a Empresa Municipal de Habitação (EMURB) criou o primeiro plano para a reurbanização da área que previa, dentre outras medidas, a sua desapropriação consensual; porém, em razão da falta de recursos financeiros, o projeto não foi levado a efeito. No ano de 1998, foram realizadas as primeiras intervenções públicas para o melhoramento urbano no local e também foi apresentado um projeto de lei à Câmara Municipal de São Paulo para a instituição da Operação Urbana Paraisópolis, que restou não aprovado, conforme Alessi (2009, p. 48-49). 
Com a aprovação do PDE de 2002, foram criadas as Zonas Especiais de Interesse Social (ZEIS), com o objetivo de implementar estratégias de planejamento urbano de acordo com a realidade de cada região do município de São Paulo. A lei de parcelamento, uso e ocupação do solo de São Paulo (Lei Municipal n. 13.885/2004) demarcou o Complexo de Paraisópolis como ZEIS-1 e ZEIS-3, ou seja, áreas ocupadas por população de baixa renda e com predominância de terrenos ou edificações subutilizadas, respectivamente. Decorrente disso, foi editado o Decreto Municipal n. 42.871/2003, atribuindo à então Secretaria Municipal da Habitação e Desenvolvimento Urbano o dever de elaborar e implementar um plano de regularização urbanística na comunidade.

O programa de regularização ganhou o nome de "Nova Paraisópolis". Seu objetivo precípuo era realizar intervenções em áreas de médio e alto risco da comunidade, de acordo com as definições constantes no Plano Municipal de Redução de Riscos, elaborado pelo Instituto de Pesquisas Tecnológicas (IPT). Essas áreas se localizavam principalmente nas regiões do Antonico, Grotão e Grotinho, que eram as mais suscetíveis a alagamentos, por se localizarem próximas a córregos, a deslizamentos de encostas e a incêndios, em razão da alta concentração de domicílios precários de madeira.

Segundo Tales Cunha, à época da regularização de Paraisópolis:

[...] a política habitacional do município passava por intenso processo de reformulação cujos objetivos declarados encontram-se no Plano Municipal de Habitação 2009/2024. A Prefeitura dispunha então de um orçamento significativamente maior do que o de anos anteriores, o que, somados a aportes dos governos Federal e Estadual para a SEHAB-SP, permitiram que ocorresse um crescimento de destinação de verbas para a área (CUNHA, 2019, p. 6-7).

A Lei Municipal n. 14.062/2005, regulamentada pelo Decreto Municipal n. 47.272/2006, autorizou a Prefeitura de São Paulo a receber como doação imóveis destinados à regularização de Paraisópolis, concedendo remissões e anistias de débitos tributários incidentes sobre esses bens. Para o cálculo do potencial construtivo transferível, foi adotada uma fórmula que considerava a área do terreno doado, o seu coeficiente de aproveitamento básico e outras informações.

As primeiras ações do plano de urbanização foram realizadas ainda no ano de 2006 . $\mathrm{Na}$ primeira fase do projeto, que se estendeu até o ano de 2008, foram realizados os serviços de pavimentação de vias, a revitalização do campo do Palmeirinha (localizado na região do Grotão), a contenção de muros e a canalização do córrego do Brejo. Ademais, Maziviero e Silva (2018, p. 509510) afirmam que foram edificadas e entregues à comunidade 56 (cinquenta e seis) unidades habitacionais no conjunto Jardim Colombo A e 278 (duzentos e setenta e oito) apartamentos no 
empreendimento Campo Limpo I, da Companhia de Desenvolvimento Habitacional e Urbano do Estado de São Paulo (CDHU). Este condomínio, apesar de se localizar fora do perímetro de Paraisópolis, foi construído para atender exclusivamente aos moradores do complexo.

No início da segunda fase do projeto, em setembro de 2009, foram entregues 126 (cento e vinte e seis) apartamentos no Condomínio Paraisópolis F, na divisa das regiões do Grotinho e Grotão (SÃO PAULO, 2009). Também durante essa etapa, que se encerrou em outubro de 2010, foram concluídas as obras dos Condomínios Paraisópolis A (cento e quarenta e seis unidades), B (duzentas unidades), C (cento e oitenta e oito unidades) e D (cento e vinte e três unidades), com um total de 783 (setecentas e oitenta e três) unidades habitacionais, assim como as obras da ETEC Abdias do Nascimento, localizada próxima à Avenida Hebe Camargo, que foi uma obra realizada pelo projeto de urbanização. Também foram iniciadas as obras de ampliação das redes de água e esgoto com o objetivo de universalizar esses serviços na comunidade. Os recursos para essa segunda etapa provieram não somente do Município, mas também do Governo Federal, por meio do PAC-UAP, e do Governo do Estado de São Paulo, por meio da SABESP e da CDHU.

Uma intervenção importante realizada durante a segunda etapa de urbanização foi a construção de escadarias (ou escadões) de interseção entre as diferentes áreas do complexo, o que era necessário em razão das diferenças de relevo existentes entre as regiões. A região do Centro, por exemplo, localiza-se em uma área mais elevada em relação às demais, principalmente em relação à região do Antonico, que possui características de vale. Logo, por ser aquela região a que concentra os principais pontos comerciais e a maioria dos equipamentos sociais da comunidade, o acesso dos moradores a ela precisava ser facilitado, o que justificou a construção das escadarias.

$\mathrm{Na}$ terceira etapa do programa, compreendida entre os anos de 2010 e 2013, houve as inaugurações de equipamentos sociais, como a Assistência Médica Ambulatorial (AMA) e o Centro Educacional Unificado (CEU), e dos Condomínios Paraisópolis E (cento e vinte e sete unidades), G (quarenta e quatro unidades) e Grotinho II (quatro unidades). Segundo Werneck (2018, p. 80), outras 664 (seiscentas e sessenta e quatro) unidades habitacionais foram construídas pela Prefeitura de São Paulo em parceria com a CDHU ao longo de todo o processo de urbanização, sendo algumas delas fora do complexo, mas destinadas aos seus moradores. De acordo com Cunha (2020, p. 157-159), apenas 399 (trezentas e noventa e nove) moradias planejadas no início do projeto, que deveriam ter sido edificadas na área conhecida como Parque Sanfona, não foram concluídas até hoje por problemas na execução das obras, como a ocorrência de um grande incêndio na área no ano de 2017. 
Durante a terceira etapa, iniciaram-se, mas não foram concluídas, as obras de drenagem dos córregos Itapaiúna e Antonico, que demandaram a remoção de um número significativo de pessoas que habitavam às suas margens. De acordo com Maziviero e Silva (2018, p. 513), até o ano de 2019, as obras no córrego do Antonico haviam sofrido diversas paralisações em sua execução e ainda não tinham sido finalizadas. As obras de drenagem no córrego Itapaiúna foram terminadas fora do prazo, mas a construção de um parque linear às suas margens, que constava no projeto original, não foi levada a efeito até hoje. No final de 2019, um novo investimento foi anunciado pelo Governo do Estado e a Prefeitura de São Paulo para a construção do parque linear e a finalização da drenagem do córrego Antonico, mas as obras ainda não foram concluídas (SÃO PAULO, 2019).

Outra obra importante que constava no plano de urbanização, mas que também não foi concluída até o momento, é a da estação Paraisópolis, da linha 17-ouro, do monotrilho, que incrementaria a mobilidade dos moradores da comunidade. Quando foi concebida, sua previsão de entrega era para antes da Copa do Mundo de Futebol de 2014, pois ela seria uma das principais vias de acesso ao Estádio do Morumbi. Entretanto, com a mudança dos jogos para a Arena Corinthians, na zona leste de São Paulo, e as sucessivas paralisações da obra, a previsão de inauguração foi adiada para 2022. Ao longo dos últimos anos, os moradores de Paraisópolis vêm reivindicando o retorno das obras, e no final do ano de 2020, o Governo do Estado de São Paulo assinou uma ordem de serviço para o retorno dos trabalhos.

O plano de urbanização também não cumpriu com a meta de universalização do acesso à água e ao esgotamento sanitário, mas conseguiu ampliar consideravelmente esses serviços para alcançar $90 \%$ e $89 \%$ dos moradores da comunidade, respectivamente. Portanto, apesar de não ter contemplado todas as residências, o projeto conseguiu expandir o serviço, passando a atender principalmente as pessoas que vivem nas regiões do Grotinho e Grotão, que estavam vulneráveis à contaminação ambiental em razão da falta de saneamento. A canalização dos córregos do Brejo e do Itapaiúna também foram intervenções relevantes porque mitigaram os alagamentos em períodos de maior pluviosidade e, por consequência, melhoraram a qualidade de vida dos moradores de seus entornos. Se esse serviço tivesse sido realizado em todos os córregos da comunidade, os resultados positivos dessas intervenções seriam ainda maiores.

Figura 2 - Condomínio Paraisópolis F 


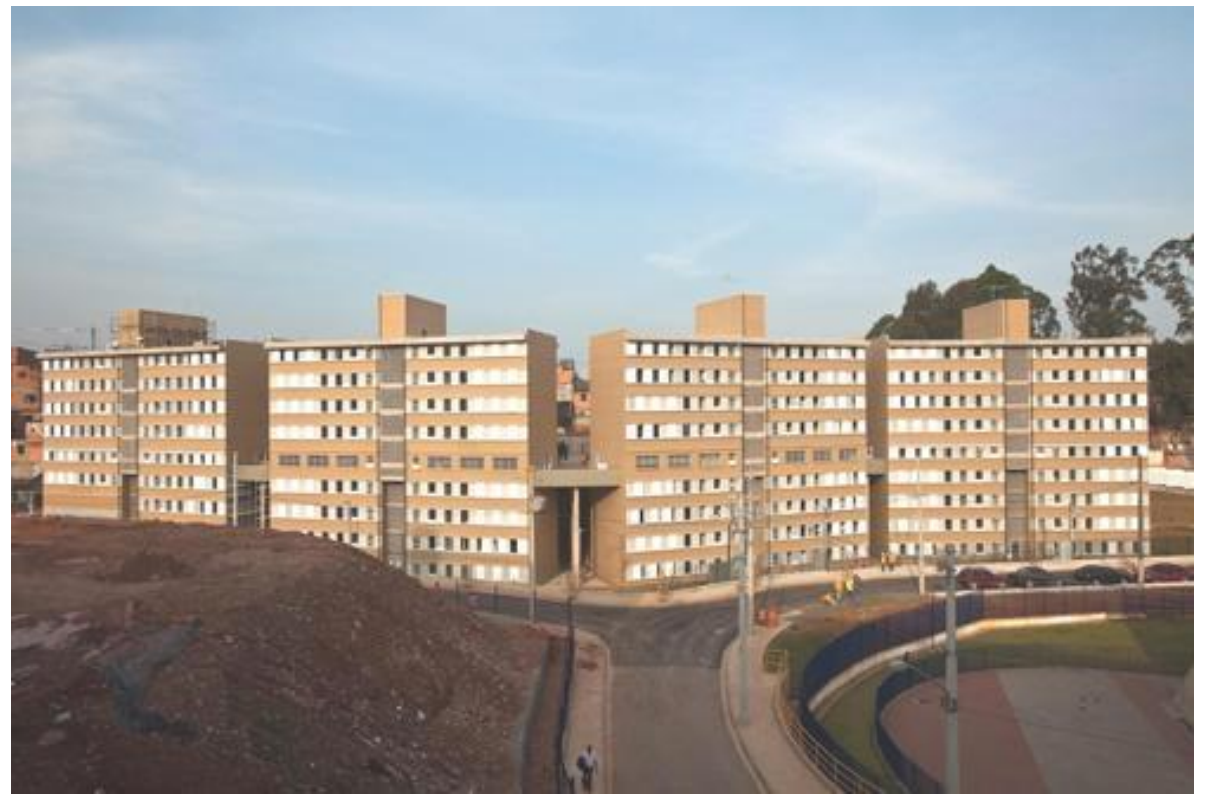

Fonte: São Paulo, 2009.

Pesquisas de campo realizadas após o projeto de regularização urbanística, como as de Rezende (2019) e Werneck (2018), identificaram a satisfação dos moradores com as obras que foram concluídas, principalmente a construção dos conjuntos habitacionais dentro da própria comunidade, o que era reivindicado desde o início do projeto. Também foram bem-recebidas a ampliação dos sistemas de água e esgoto, a inauguração dos equipamentos sociais e a abertura da Avenida Hebe Camargo, que hoje é uma via alternativa à Avenida Giovanni Gronchi, que tem tráfego intenso na zona sul da cidade. Lado outro, as mesmas pesquisas constataram a percepção negativa dos moradores em relação às obras inconclusas e em relação ao não reassentamento de centenas de famílias desapropriadas que ainda se encontram dependentes do aluguel social da Prefeitura de São Paulo.

Diante disso, é possível formular algumas considerações sobre o projeto de regularização analisado, principalmente sobre o uso da TDC. Segundo dados do município de São Paulo, até o ano de 2013 , cerca de 60 mil metros quadrados haviam sido doados por meio da TDC para o projeto "Nova Paraisópolis", sendo que a quase totalidade desse percentual foi utilizada para a construção de HIS; o pequeno percentual restante foi destinada à abertura da Avenida Hebe Camargo em uma área desapropriada para abrigar HIS.

De acordo com documentos oficiais de março de 2021, 211 (duzentos e onze) pedidos de doação foram apresentados após a edição da Lei Municipal n. 14.062/2005 e do Decreto Municipal n. 47.272/2006, dos quais 99 (noventa e nove) foram deferidos, 100 (cem) foram indeferidos, em 11 
(onze) houve desistências dos proprietários e um ainda se encontra em análise. Dos imóveis doados, apenas 24 (vinte quatro) tinham dívidas com a Fazenda Pública municipal. A maioria dos requerimentos de doação foi feita por moradores do Grotão, mas a maior parte dos pedidos aceitos foi da região do Antonico.

Figura 3 - Mapa dos imóveis doados em Paraisópolis até 2013

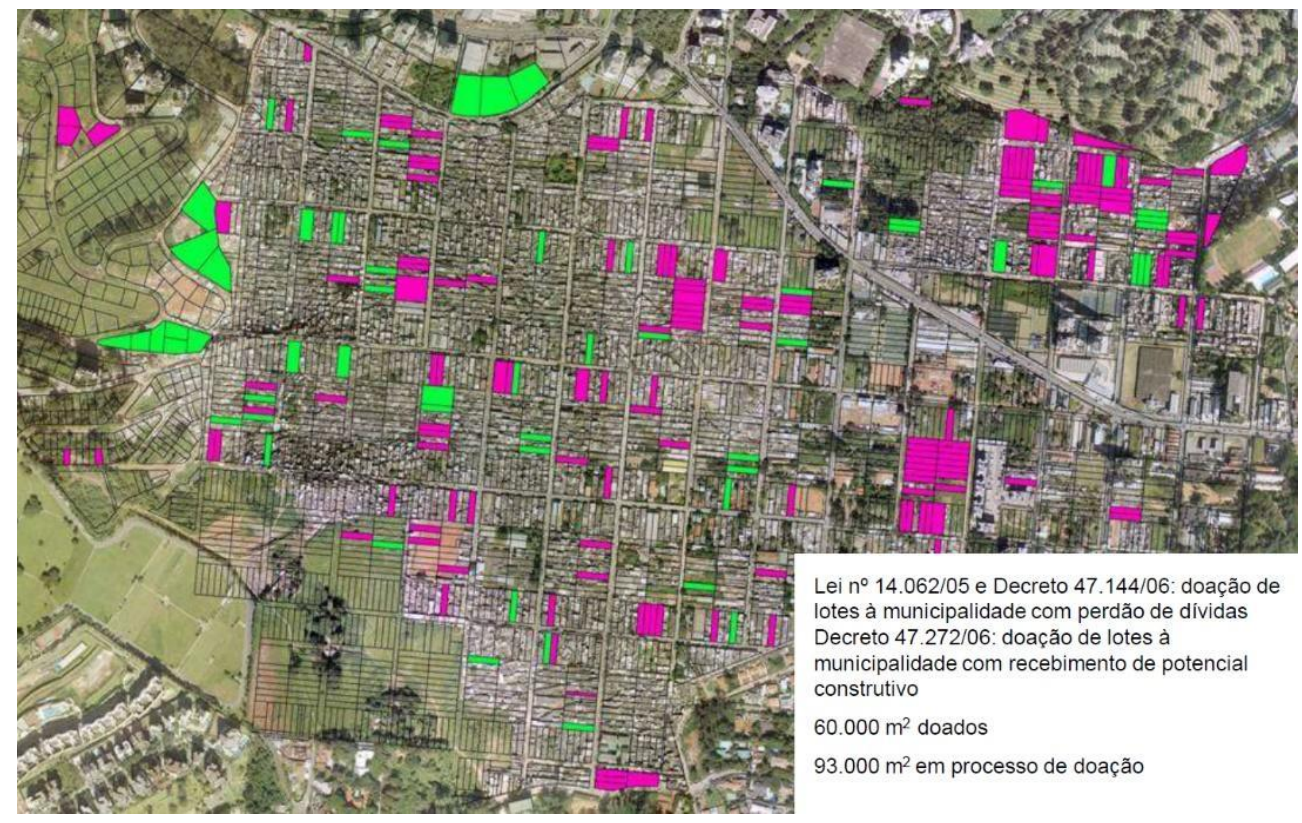

Fonte: São Paulo, 2013.

O município de São Paulo buscou regulamentar o uso da TDC em Paraisópolis de forma clara por leis e decretos que deram segurança jurídica a sua implementação, o que foi positivo sob as perspectivas jurídica e do planejamento urbano. Contudo, depreende-se que os resultados gerados pela TDC foram restritos à habitação e, em uma pequena parte, à Avenida Hebe Camargo. Para a realização das outras intervenções, foram feitas remoções de moradores. O Grotão foi a região que mais fez pedidos de doação de imóveis, mas foi também a que mais sofreu com as desapropriações, e esse dado merece atenção, pois o objetivo da TDC era evitar as remoções e todos os efeitos negativos que elas geram. Dessa forma, se os requerimentos de doação dos moradores da região tivessem sido deferidos, certamente o número de desapropriações seria menor, assim como o de famílias que hoje se encontram recebendo o aluguel social.

Embora a TDC e as adaptações no projeto tenham reduzido o número de remoções planejadas de 30\% (trinta por cento) para 10\% (dez por cento) das residências, algumas desapropriações ainda foram realizadas, principalmente nas áreas de risco geotécnico (a maioria na região do Grotão), em 
imóveis necessários para as obras de infraestrutura que não haviam sido doados e na área conhecida como "Fazendinha" (lindeira à região do Grotão), que possui cerca de 200 (duzentos) metros quadrados. Em razão disso, o número de famílias inseridas no aluguel social municipal durante o projeto cresceu consideravelmente a partir de 2009. Segundo Tales Cunha (2020, p. 182), em agosto de 2019, 4.093 (quatro mil e noventa e três) famílias do Complexo de Paraisópolis recebiam o benefício, correspondendo ao maior contingente do programa. Segundo o autor, esse quadro é resultado da discrepância entre o número de desapropriações e a quantidade de HIS construídas na comunidade, que foi insuficiente para atender ao passivo habitacional (CUNHA, 2019, p. 2).

Figura 4 - Área desapropriada em destaque (Fazendinha)

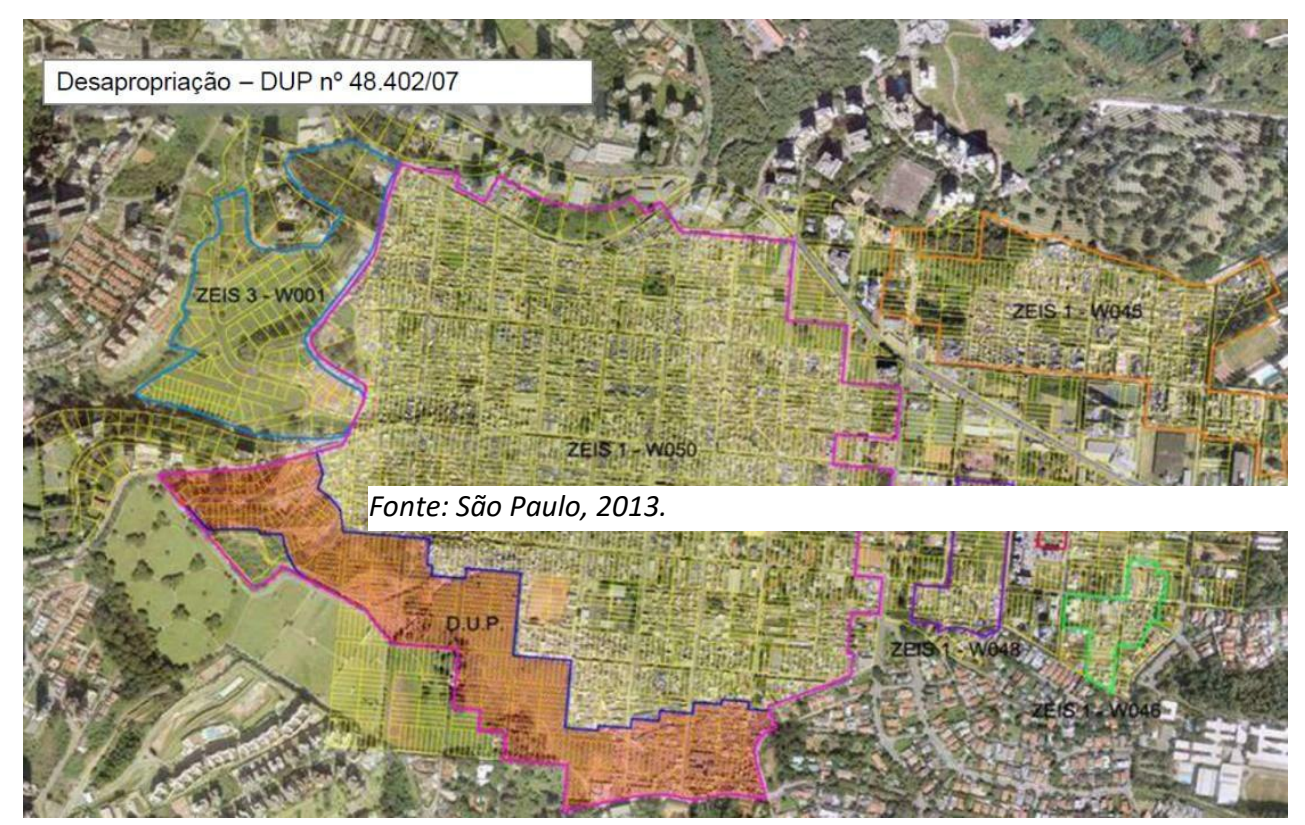

O deslinde dessa questão habitacional tornou-se ainda mais complexo após a edição do PDE de São Paulo de 2014 (Lei Municipal n. 13.430/2014), pois parte de Paraisópolis foi gravada como ZEIS5, que "são lotes ou conjunto de lotes, preferencialmente vazios ou subutilizados, situados em áreas dotadas de serviços, equipamentos e infraestruturas urbanas, onde haja interesse privado em produzir empreendimentos habitacionais de mercado popular e de interesse social" (artigo 45, V). Nesse tipo de ZEIS, é permitido que o mínimo de HIS seja reduzido de $60 \%$ (sessenta por cento), previsto para as 
demais ZEIS do município, para 40\% (quarenta por cento). O PDE também dispõe que as habitações de mercado popular (HMP) devem ser estimuladas principalmente nas ZEIS-5 (artigo 292, VIII), o que exclui a maioria dos moradores de Paraisópolis pelo critério de renda.

Essa ZEIS-5 localiza-se ao sul da região do Grotinho, compreendendo uma área que foi muito beneficiada pelas obras de urbanização, sobretudo pela abertura da Avenida Hebe Camargo e a instalação de equipamentos públicos. A mudança de zoneamento da área mostra-se interessante para o setor imobiliário da região em razão da infraestrutura construída no local, que permite uma nova frente de expansão imobiliária por meio das HMP. Entretanto, essa mudança pode comprometer o reassentamento das famílias desapropriadas que se encontram dependentes do auxílio aluguel, pois os novos empreendimentos privados que se instalarem na região deverão destinar apenas $40 \%$ (quarenta por cento) de suas unidades para HIS, o que não será suficiente para solucionar a questão.

Dessa forma, mostra-se de rigor que o Poder Público atue para garantir que as famílias que recebem o auxílio aluguel sejam reassentadas o mais breve possível, de modo a evitar que essa situação transitória e excepcional continue se prolongando indefinidamente. Certamente, as HIS dos futuros empreendimentos localizados em ZEIS-5 não serão suficientes para atender à demanda social criada pelas remoções, e a solução para esse problema dependerá necessariamente de uma iniciativa estatal.

Um aspecto importante do projeto foi a descentralização dos novos equipamentos urbanos instalados na comunidade, fora da região do Centro. Como exemplos, tem-se que a AMA, a UBS, o CAPS e o CEU foram construídos na região do Grotão, próximos aos conjuntos habitacionais Paraisópolis A, B e D, assim como o pavilhão social, localizado ao lado dos condomínios Paraisópolis $\mathrm{G}$ e Vila Andrade G. A escola de música, que está com as obras paralisadas, também se encontra na região do Grotão. A ETEC Abdias do Nascimento foi construída na região do Grotinho. Essa descentralização foi positiva, porque aproximou os serviços públicos das regiões mais pobres da comunidade, permitindo que as necessidades da população sejam atendidas de forma mais eficiente. Ademais, essa descentralização pode contribuir para criar subcentralidades importantes no complexo, no que se refere tanto à oferta de serviços públicos quanto à instalação de negócios particulares, que podem oferecer novas oportunidades de emprego para os moradores dessas regiões.

Por certo, o projeto "Nova Paraisópolis" não foi o primeiro a apresentar problemas ao longo de sua execução e a entregar resultados aquém dos esperados tanto pelo Poder Público quanto pela sociedade, pois projetos semelhantes também passaram por dificuldades e, em muitos deles, não se 
conseguiu a integração efetiva da comunidade à cidade formal. Como exemplo, Izaga e Pereira (2014) apresentam as experiências de urbanização de algumas favelas do Rio de Janeiro que não concluíram todas as obras planejadas pelo Poder Público, fato que repercutiu nas demais medidas de regularização.

No caso de Paraisópolis, apesar de certas intervenções não terem sido realizadas, pode-se inferir que as obras concluídas melhoraram a vida da comunidade, sobretudo porque facilitaram o acesso dos moradores a equipamentos públicos, como a ETEC, o AMA e o CEU. Além disso, a construção de HIS permitiu que centenas de famílias tivessem acesso à moradia digna na própria comunidade e à ampliação das redes de saneamento básico, o que melhorou a qualidade ambiental de muitas áreas do complexo. Conclui-se que o projeto foi interessante porque fez uso da TDC, que é um instrumento pouco utilizado em processos de regularização, e seus resultados podem influenciar ações semelhantes no futuro.

\section{CONSIDERAÇÕES FINAIS}

O programa "Nova Paraisópolis" foi certamente uma ação de grande importância não somente para a comunidade beneficiada, mas também para toda a cidade de São Paulo, porque resultou em melhorias significativas nas áreas de saúde, moradia e mobilidade urbana. Contudo, o projeto não solucionou os problemas estruturais que afligem Paraisópolis e que impedem que seus moradores usufruam plenamente de seus direitos sociais.

A regularização de Paraisópolis ocorreu no momento em que planejamento urbano nacional buscava a urbanização de aglomerados subnormais por meio de grandes obras de infraestrutura que pretendiam melhorar a vida dos moradores. Considerando também que o projeto coincidiu com um momento de crescimento econômico do país e do setor imobiliário nacional, grandes aportes financeiros foram destinados ao seu financiamento, tanto pelo município de São Paulo quanto pelo Estado de São Paulo e o Governo Federal. Assim, é interessante notar como o projeto marca uma mudança de paradigma em relação ao tratamento que era conferido pelo Estado às favelas no início do século XX, quando se buscava a erradicação desses espaços por meio do uso da força policial.

A pesquisa buscou compreender como a TDC foi empregada na regularização de Paraisópolis, por meio do incentivo à doação de terrenos para a execução das obras de urbanização. Concluiu-se que o instrumento, aliado a adaptações no projeto original, reduziu o número de desapropriações, as quais se concentraram em áreas pontuais da comunidade. Entretanto, ainda assim se identificou um 
crescimento exponencial no número de famílias que passaram a receber o auxílio aluguel ao longo das obras e muitas dessas famílias permanecem sem perspectivas de reassentamento na própria comunidade. Portanto, a TDC não foi suficiente para suprir o déficit habitacional que existia na favela e o número de desapropriações aumentou esse passivo, tornando-o de difícil solução atualmente.

Além da construção de HIS, a ampliação das redes de água e esgoto, a inauguração de equipamentos sociais e a abertura de vias públicas foram os principais resultados positivos decorrentes da regularização. A quase totalidade do potencial construtivo doado pela TDC foi utilizada para a edificação de HIS e uma pequena parte para a abertura da Avenida Hebe Camargo. A partir dos dados de pesquisas de campo realizadas após a urbanização, foi possível identificar a satisfação dos moradores com essas obras. Por outro lado, os principais resultados negativos do programa foram a inconclusão de outras obras, como a canalização de córregos, e o não reassentamento de centenas de famílias removidas que ainda hoje se encontram dependentes do auxílio aluguel.

Conquanto haja a necessidade de aprofundamento dos estudos sobre as experiências contemporâneas de regularização de favelas no país, o caso de Paraisópolis permite inferir que o Poder Público precisa atentar para o uso adequado dos instrumentos urbanísticos em projetos dessa natureza, sob pena de não concretizar os direitos dos moradores desses locais e ainda agravar o problema da falta de moradia por meio das desapropriações. Acredita-se que um projeto de regularização deve necessariamente buscar a coesão social dos espaços urbanos para tornar as cidades mais igualitárias e integradoras, o que, para ser alcançado, depende também da implementação de políticas de assistência social que promovam saúde, emprego, lazer e segurança aos moradores das comunidades.

Sem a pretensão de generalizar os resultados de um caso específico, assevera-se que as políticas de regularização de favelas no país ainda precisam avançar para garantir a inclusão social dos moradores das comunidades a partir da universalização de seus direitos, permitindo um acesso equitativo à cidade e às suas infraestruturas.

\section{REFERÊNCIAS}

ALESSI, N. A. (2009). Formam-se favelas e ganham importância no cenário urbano São Paulo: Heliópolis e Paraisópolis. 2009. 169 f. Dissertação (Mestrado) - Programa de Pós-graduação em Geografia Humana, Faculdade de Filosofia, letras e Ciências Humanas, Universidade de São Paulo, São Paulo, 2009. 
ALOCHIO, L.H.A. O direito do urbanismo e a transferência do direito de construir: requisitos de limitação nas leis locais. Revista de Direito Administrativo, Rio de Janeiro, v. 249, p. 119-141, 2008.

ANTONUCCI, D.; SAMORA, P. R. A política nacional de habitação e a urbanização de assentamentos precários no Brasil contemporâneo (2001-2015). In: IV Encontro da Associação Nacional de Pesquisa e Pós-Graduação em Arquitetura e Urbanismo. Anais. Porto Alegre, p. 1-17, 2016.

BALBIM, R.; KRAUSE, C. Produção social da moradia: um olhar sobre o planejamento da Habitação de Interesse Social no Brasil. Revista Brasileira de Estudos Urbanos e Regionais, Rio de Janeiro, v. 16, n. 1, p. 189-201, 2014.

BARCELLAR, I.; FURTADO, F.; NEWLANDS, A. A experiência municipal recente com a Transferência do Direito de Construir no Brasil: imprecisões, lacunas e oportunidades de aperfeiçoamento. In: III Congresso Iberoamericano de Suelo Urbano. Anais. Curitiba, p. 1-17, 2017.

BITENCOURT, A. P. M. A transferência do direito de construir para a conservação do patrimônio cultural: a experiência da cidade de Curitiba. 2005. 205 f. Dissertação (Mestrado) - Programa de Pósgraduação em Desenvolvimento Urbano, Centro de Artes e Comunicação, Universidade Federal de Pernambuco, Recife, 2005.

BRASIL, F. K. A. L. Arquitetura vernácula da habitação popular: análise das mudanças e permanências das características arquitetônicas da habitação popular decorrentes da intervenção de fatores financeiros, técnicos e organizacionais. 2003. 141 f. Dissertação (Mestrado) - Programa de Pós-graduação em Desenvolvimento Urbano, Centro de Artes e Comunicação, Universidade Federal de Pernambuco, Recife, 2003.

BRASIL. 11 Balanço completo do PAC 2: 4 anos (2011-2014). 2014. Disponível em: http://pac.gov.br/pub/up/relatorio/f9d3db229b483b35923b338906b022ce.pdf. Acesso em: 05 dez 2020.

BRASIL. 70 Balanço do PAC 2015-2018. 2018. Disponível em: http://pac.gov.br/pub/up/relatorio/37855886e9418dce3f9baf3128444233.pdf. Acesso em: 05 dez 2020.

CARDOSO, A. L. Avanços e desafios na experiência brasileira de urbanização de favelas. Cadernos Metrópole, São Paulo, s/v, n. 17, p. 219-240, 2007.

CARDOSO, A. L.; ARAGÃO, T. A.; JAENISCH, S. T. "Vinte e dois anos de política habitacional no Brasil: da euforia à crise". In: CARDOSO, A. L.; ARAGÃO, T. A.; JAENISCH, S. T. (org.). Vinte e dois anos de política habitacional no Brasil: da euforia à crise. Rio de Janeiro: Letra Capital, 2017.

CARVALHO FILHO, José dos Santos. Comentários ao Estatuto da Cidade. 5a ed. rev., ampl. e atual. São Paulo: Atlas, 2013.

CUNHA, T. F. S. "A conta não fecha": o boom do auxílio aluguel em São Paulo: Uma análise a partir do caso da favela de Paraisópolis. 2020. 216 f. Dissertação (Mestrado) - Programa de Pós-graduação em Arquitetura e Urbanismo, Faculdade de Arquitetura e Urbanismo, Universidade de São Paulo, São Paulo, 2020.

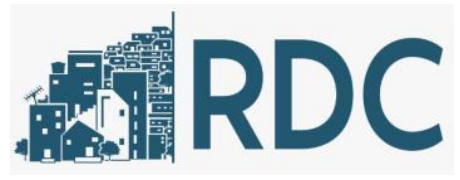

Rev. Dir. Cid., Rio de Janeiro, Vol. 14, N.01., 2022, p. 333-357.

Pedro Rodrigo Campelo Lima e Thiago Marrara

DOI: 10.12957/rdc.2022.60876| ISSN 2317-7721 
CUNHA, T. F. S. O auxílio aluguel e o programa municipal de urbanização de favelas: uma análise a partir da urbanização da favela de Paraisópolis. In: XVIII Encontro da Associação Nacional de Pesquisa e Pós-Graduação em Arquitetura e Urbanismo. Anais. Natal, p. 1-16, 2019.

DENALDI, R.; MORETTI, R.; PAIVA, C.; NOGUEIRA, F.; PETRAROLLI, J. Urbanização de favelas na Região do $A B C$ no âmbito do Programa de Aceleração do Crescimento-Urbanização de Assentamentos Precários. Cadernos Metrópole, São Paulo, v. 18, n. 35, p. 101-118, 2016.

FONTES, M. C. L. P. Operação urbana e habitação de interesse social. 2011. 173 f. Tese (Doutorado) - Programa de Pós-graduação em Arquitetura e Urbanismo, Faculdade de Arquitetura e Urbanismo, Universidade Presbiteriana Mackenzie, São Paulo, 2011.

IZAGA, F.; PEREIRA, M. S. A mobilidade urbana na urbanização das favelas no Rio de Janeiro. Cadernos do Desenvolvimento Fluminense, Rio de Janeiro, s/v, n. 4, p. 88-115, 2014.

LOURO E SILVA, H.; CAMPOS, C. M. O mercado imobiliário residencial na Operação Urbana Centro, São Paulo (1985-2006). Revista Projetar, Natal, v. 1, n. 2, p. 70-80, 2016.

MAZIVIERO, M. C.; SILVA, A. S. O caso do Complexo Paraisópolis em gestões: diferenças conceituais em programas de intervenção em favelas em São Paulo. Revista Brasileira de Gestão Urbana, Curitiba, v. 10, n. 3, p. 500-520, 2018.

NOGUEIRA, K. M. S. Outorga Onerosa do Direito de Construir: uma exploração da aplicação na cidade de São Paulo a partir do mercado imobiliário. 2019. 157 f. Dissertação (Mestrado) - Programa de Pós-graduação em Planejamento e Gestão do Território, Universidade Federal do ABC, São Bernardo do Campo, 2019.

PERETTO, F. T. Transferência do direito de construir em São Paulo: concepção e gestão no contexto do mercado de direitos de construir. 2020. 255 f. Dissertação (Mestrado) - Programa de Pósgraduação em Arquitetura e Urbanismo, Faculdade de Arquitetura e Urbanismo, Universidade de São Paulo, São Paulo, 2020.

PIZARRO, E. P. Interstícios e interfaces urbanos como oportunidades latentes: o caso da Favela de Paraisópolis. 2014. 370 f. Dissertação (Mestrado) - Programa de Pós-graduação em Arquitetura e Urbanismo, Faculdade de Arquitetura e Urbanismo, Universidade de São Paulo, São Paulo, 2014.

REZENDE, W. S. Urbanidade experiencial: situações e interações no cotidiano de Paraisópolis, São Paulo. 2019. 379 f. Tese (Doutorado) - Programa de Pós-graduação em Arquitetura e Urbanismo, Faculdade de Arquitetura e Urbanismo, Universidade Presbiteriana Mackenzie, São Paulo, 2019.

ROLNIK, R.; PEREIRA, A. L. dos S.; MOREIRA, F. A.; ROYER, L. O.; IACOVINI, R. F. G.; NISIDA, V. C.; LOPES, A. P. O.; ROSSI, L. G. A. O programa Minha Casa Minha Vida nas Regiões Metropolitanas de São Paulo e Campinas: aspectos socioespaciais e segregação. Cadernos Metrópole, São Paulo, v. 17, n. 33, p. 127-154, 2015.

RUBIO, V. M. Programa de urbanização e os desafios para integração da favela à cidade: avanços e descompassos de uma política pública em Osasco - SP (2005-2016). 2017. 483 f. Tese (Doutorado) - 
Programa de Pós-graduação em Arquitetura e Urbanismo, Faculdade de Arquitetura e Urbanismo, Universidade Presbiteriana Mackenzie, São Paulo, 2017.

SANTORO, P. F.; PERETTO, F. T.; OKSMAN, S. PIU Central e o debate da Transferência de Direitos de Construir públicos feita por privados. 2018. Disponível em: http://www.labcidade.fau.usp.br/piucentral-e-o-debate-da-transferencia-de-direitos-de-construir-publicos-feita-por-privados/. Acesso em: 16 dez. 2020.

SANTOS, A. N. A "participação" dos favelados em projetos de (re)urbanização: o caso do PAC no Pavão-Pavãozinho-Cantagalo. 2017. 189 f. Dissertação (Mestrado) - Programa de Pós-graduação em Serviço Social, Departamento de Serviço Social, Pontifícia Universidade Católica do Rio de Janeiro, Rio de Janeiro, 2017.

SÃO PAULO. Doria anuncia Projeto Comunidade com investimento de R\$ 250 milhões em

Paraisópolis. 2019. Disponível em: https://www.saopaulo.sp.gov.br/sala-de-imprensa/doria-anunciaprojeto-comunidade-com-investimento-de-r-250-milhoes-em-paraisopolis/. Acesso em: 16 dez 2020.

SÃO PAULO. Prefeito e governador entregam 126 apartamentos em Paraisópolis. 2009. Disponível em: https://www.prefeitura.sp.gov.br/cidade/secretarias/subprefeituras/noticias/?p=4361. Acesso em: 16 dez 2020.

SÃO PAULO. Programa Paraisópolis: regularização fundiária. 2013. Disponível em: http://paraisopolis.org/wp-content/uploads/2008/05/Regulariza\%C3\%A7\%C3\%A3o-FundiariaConselho-Gestor.pdf. Acesso em 16 jan. 2021.

SCHWARCZ, L. M.; STARLING, H. M. Brasil: uma biografia. 1 ed. São Paulo, Companhia das Letras, 2015.

SOUZA, A. P.; PERETTO, F.; SEO, H. H. K. O Parque Augusta e o milagre da multiplicação de potencial construtivo: o caso das doações de imóveis para implantação de Parques Municipais no PDE-SP de 2014. In: XVIII Encontro da Associação Nacional de Pesquisa e Pós-Graduação em Arquitetura e Urbanismo. Anais. Natal, p. 1-20, 2019.

SOUZA, G. P. O desenvolvimento do programa Habitar Brasil no conjunto residencial Homero Linhares - Miracema/RJ: uma análise da participação popular e da qualidade de vida. 2008. $201 \mathrm{f}$. Dissertação (Mestrado) - Programa de Pós-graduação em Políticas Sociais, Centro de Ciências do Homem, Universidade Estadual do Norte Fluminense, Campos dos Goytacazes, 2008.

WERNECK, R. M. As percepções dos moradores do Grotão da favela de Paraisópolis/SP sobre o processo de urbanização: as condições de vida e o direito à moradia. 2018. 121 f. Dissertação (Mestrado) - Programa de Pós-graduação em Serviço Social, Faculdade de Ciências Sociais, Pontifícia Universidade Católica de São Paulo, São Paulo, 2018.

Sobre os autores:

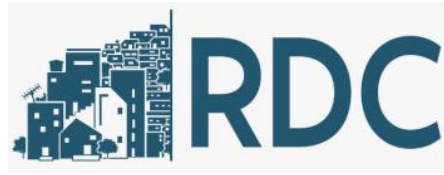

Rev. Dir. Cid., Rio de Janeiro, Vol. 14, N.01., 2022, p. 333-357.

Pedro Rodrigo Campelo Lima e Thiago Marrara

DOI: $10.12957 /$ rdc.2022.60876| ISSN 2317-7721 


\section{Thiago Marrara}

Livre-docente pela Universidade de São Paulo (USP). Doutor em Direito Público pela Universidade de Munique (LMU). Professor associado de Direito Administrativo da Universidade de São Paulo (USP). Editor da Revista Digital de Direito Administrativo (RDDA). Advogado-consultor. Universidade de São Paulo - USO, São Paulo, SP, Brasil

Lattes: http://lattes.cnpq.br/5001783167154079. Orcid: https://orcid.org/0000-0002-1524-568X

E-mail: marrara@usp.br

\section{Pedro Rodrigo Campelo Lima}

Mestrando em Direito pela Universidade de São Paulo (USP). Bacharel em Direito pela Universidade Federal de Lavras (UFLA). Advogado. Universidade de São Paulo - USO, São Paulo, SP, Brasil

Lattes: http://lattes.cnpq.br/8921948076714110. Orcid: https://orcid.org/0000-0002-1524-568X

E-mail: pedro.lima_ap@hotmail.com

Os autores contribuíram igualmente para a redação do artigo. 